\title{
A model for particle formation and growth in the atmosphere with molecular resolution in size
}

\author{
K. E. J. Lehtinen and M. Kulmala \\ Helsinki University, Dept. Physical Sciences, P.O. Box 64, 00014 Univ. of Helsinki, Finland \\ Received: 23 August 2002 - Published in Atmos. Chem. Phys. Discuss.: 28 October 2002 \\ Revised: 23 January 2003 - Accepted: 3 February 2003 - Published: 21 February 2003
}

\begin{abstract}
The formation and growth of atmospheric aerosol particles is considered using an exact discrete method with molecular resolution in size space. The method is immune to numerical diffusion problems that are a nuisance for typical simulation methods using a sectional representation for the particle size distribution. For condensational growth, a slight modification is proposed for the Fuchs-Sutugin expression, which improves the prediction of the growth rate of nanosized particles by as much as a factor of two. The presented method is applied to particle formation in a Finnish Boreal forest and is shown to capture the essential features of the dynamics quite nicely. Furthermore, it is shown that the growth of the particles is roughly linear, which means that the amount of condensable vapour is constant (of the order $\left.10^{13} 1 / \mathrm{m}^{3}\right)$.
\end{abstract}

\section{Introduction}

The formation and growth of atmospheric aerosols has recently received growing experimental and theoretical interest due to climate and health related effects of fine particles (Charlson and Wigley, 1994; Dockery and Pope, 1994). The increased aerosol concentrations are largely due to secondary particle production, i.e. homogeneous nucleation and subsequent growth from vapours. Instrument techniques for measuring freshly formed particle concentrations have been recently developed, and particles with a diameter of about $3 \mathrm{~nm}$ can be detected. These small particles have been found in the free troposphere (Clarke, 1992; Schröder and Ström, 1997; Raes et al., 1997), in the marine boundary layer (Covert et al., 1992; Hoppel et al., 1994; O'Dowd et al., 1999), in the vicinity of evaporating clouds (Hegg et al., 1991), in Arctic areas (Wiedensohler et al., 1996; Pirjola et al., 1998),

Correspondence to: K. E. J. Lehtinen

(kari.lehtinen@helsinki.fi) in urban areas and in stack plumes (Kerminen and Wexler, 1996), in continental boundary layer (Birmilli and Wiedensohler, 2000) and recently also in boreal forests (Mäkelä et al., 1997; Kulmala et al., 1998, 2001a).

The freshly formed aerosols become climatically important only if they are able to grow to sizes of $50 \mathrm{~nm}$ and larger. Particles in this size range can act as cloud condensation nuclei, and therefore they may contribute to the so-called indirect aerosol cooling effect of the climate. Furthermore, if the particles grow to sizes above $100 \mathrm{~nm}$, they become to scatter light very efficiently, and have thereby a direct cooling effect on the climate. Whether or not the new particles ever reach these sizes is to a large extent decided while they are still smaller than $10 \mathrm{~nm}$ (Kulmala et al., 2000, 2001b). Due to their Brownian movement, particles with diameters of a few nm coagulate very efficiently with larger particles, which implies that the freshly nucleated particles have to grow fairly rapidly (within a few hours) past the $10 \mathrm{~nm}$ limit or they will be lost in the collision processes (Kulmala et al., 2000). Such growth is possible only if there is a supersaturated vapour present at concentrations above $10^{7}$ molecules per cubic centimeter of air (Kulmala et al., 2001b). In order to determine the climatic importance of atmospheric nucleation events, we need to know what are the vapours causing the particle growth, what are the chemical mechanisms controlling their formation, and what if any is the anthropogenic influence on their concentrations. At the moment, we only know that the growth of particles after continental nucleation events is with high probability caused by organic vapours (O'Dowd et al., 2002). The longest time sequence of observations is from Hyytiälä $\left(61^{\circ} 51^{\prime} \mathrm{N} 24^{\circ} 17^{\prime} \mathrm{E}\right)$ in Finland, where measurements with a differential mobility particle sizer (DMPS, measures the aerosol number concentration from 3-610 nm dry diameter), begun in January 1996. Up to May 2002 there were around 300 days with nucleation. The particle formation is usually observed in the late morning as the appearance of $3 \mathrm{~nm}$ particles at the lower size range of

(C) European Geosciences Union 2003 
the DMPS (Mäkelä at al., 1997, Kulmala et al., 2001a).

In this paper we consider the condensational growth of freshly nucleated particles. The methodology includes three novel techniques: (1) an improved model in free molecular regime condensation, based on a simple modification to the well known Fuchs-Sutugin expression (Fuchs and Sutugin, 1971) (2) a discrete method for solving the general dynamic equation (GDE, Friedlander, 2000) for the particle size distribution, that is free of numerical discretization errors and (3) analysis of the time evolution of point wise values of the measured particle size distribution to validate the assumption of a constant concentration of condensable vapour, resulting in linear growth in terms of particle diameter.

\section{Theory}

\subsection{Free-molecular condensation}

The traditional way to describe free-molecular condensation (Seinfeld and Pandis, 1998) is to assume vapour molecules as point masses and use the so-called Fuchs-Sutugin expression (Fuchs and Sutugin, 1971) for the particle growth rates. However, this approach induces serious errors when the particles are very small (say, under $10 \mathrm{~nm}$ ). Then, it is not possible anymore to ignore molecular dimensions in comparison with particle size. Also, the particle diffusion coefficient, which typically is also assumed negligible, has to be accounted for. Our approach is to use the following equation for the collision rate of molecules with particles $\beta_{1 i}$.

$$
\begin{aligned}
\beta_{1 i} & =2 \pi\left(d_{1}+d_{i}\right)\left(D_{1}+D_{i}\right) \\
& \cdot \frac{K n+1}{0.377 K n+1+\frac{4}{3 \alpha}\left(K n^{2}+K n\right)},
\end{aligned}
$$

which is comprised of the continuum regime condensation rate multiplied by the semi-empirical Fuchs-Sutugin interpolation function (Fuchs and Sutugin, 1971) (the last term in the equation). It has been obtained by fitting Sahni's (1966) numerical results for the solution of Boltzmann's equation, and extends the validity of Eq. (1) to cover all particle sizes. In Eq. (1), $d_{1}$ and $d_{i}$ are the diameters and $D_{1}$ and $D_{i}$ the diffusion coefficients of the condensing molecule and particle in class $i$, respectively. The factor $\alpha$ is the mass accommodation coefficient. Traditionally, $d_{1}$ and $D_{i}$ are left out of Eq. (2) (Seinfeld and Pandis, 1998) since the molecular diameter is typically negligible compared with particle diameter and particle diffusion coefficient negligible compared with molecular diffusion coefficient. However, if one is interested in the really initial stages of particle growth, i.e. when their diameters are of order $1 \mathrm{~nm}$, such approximations are obviously not possible.
In this formulation, to obtain correct asymptotical behaviour in the small particle limit, the Knudsen number Kn should be defined as

$K n=\frac{2 \lambda}{\left(d_{1}+d_{i}\right)}$

in which the mean free path of the condensation process is

$\lambda=\frac{3\left(D_{1}+D_{i}\right)}{\sqrt{\bar{c}_{1}^{2}+\bar{c}_{i}^{2}}}$.

Here $c_{1}$ and $c_{i}$ are the thermal speeds of the molecule and particle, respectively. The diffusion coefficients are calculated using simple kinetic theory. Again, the difference to the standard way is that now the molecular dimensions as well as particle diffusion are not neglected. This modification of condensation theory approaches free-molecular coagulation theory in the limit of free-molecular particles.

\subsection{Discrete solution of the size distribution}

Next, we turn to the issue of solving the particle size distribution in detail. The aerosol general dynamic equation (Friedlander, 2000) is typically solved using either a sectional method with fixed sections or with moving sections. The idea behind the sectional method is to approximate the particle size distribution with a histogram. Then, the various aerosol dynamical processes (nucleation, condensation, coagulation, deposition, transport) are treated by modelling the concentration and/or location of each section. Using fixed sections is naturally ideal for nucleation and coagulation processes. However, for condensation/evaporation this method has a serious drawback, numerical diffusion (Zhang et al., 1999) It can be circumvented by using moving sections then, however, we might encounter a situation in which there are no sections in a size range of importance (for example, the size of nucleating particles). In this paper, we present an approach that has neither of the abovementioned drawbacks: the size sections are fixed but the spacing is done moleculeby-molecule. Then, the actual physics of the problem are mimicked in detail, and provided that the computational burden is not insuperable, the method should, in principle, be free of any discretization errors.

The dynamics of nucleation mode particle size distribution is simulated using a discrete coagulation scheme with appropriate sources:

$$
\begin{aligned}
& \frac{\mathrm{d} N_{1}}{\mathrm{~d} t}=I_{1}-k^{*} I_{k^{*}}-N_{1} \sum_{i=k^{*}}^{\infty} \beta_{1 i} N_{i} \\
& \frac{\mathrm{d} N_{k^{*}}}{\mathrm{~d} t}=I_{k^{*}}-\beta_{1 k^{*}} N_{1} N_{k^{*}}-N_{k^{*}} \sum_{i=k^{*}}^{\infty} \beta_{k^{*}, i} N_{k^{*}} N_{i} \\
& \frac{\mathrm{d} N_{k}}{\mathrm{~d} t}=\beta_{1, k-1} N_{1} N_{k-1}+\frac{1}{2} \sum_{i=k^{*}}^{k-k^{*}} \beta_{i, k-i} N_{i} N_{k-i}
\end{aligned}
$$




$$
-\beta_{1 k} N_{1} N_{k}-N_{k} \sum_{i=k^{*}}^{\infty} \beta_{i k} N_{i} \quad\left(k>k^{*}\right)
$$

using the Fuchs expression (Fuchs and Sutugin, 1971) for the collision frequency functions $\beta_{i j}$. In our approach, we select class 1 to represent molecules. $I_{1}$ is a source rate for the molecules. Class $k^{*}$ represents the smallest stable particles, with $I_{k^{*}}$ as their nucleation rate. The particle dynamics, in addition to the nucleation source, is driven by coagulation and condensation/evaporation. In this method, condensation is treated as collisions of classes i with class 1 , and is thus free of any numerical diffusion problems. The condensation rates $\beta_{1 i}$ are calculated from the modified Fuchs-Sutugin expressions as explained before. In equations 4 , the evaporation of particles is not taken into account. However, possible surface pressures of the vapours can be straightforwardly introduced into the equations, resulting essentially in the birth and death formalism by Goodrich (1964).

\section{Results}

An important practical system to investigate the improved growth expression is the growth of particles from nucleation size (say $1 \mathrm{~nm}$ in diameter) to $3 \mathrm{~nm}$. The reason for this is that available particle size distribution measurement instrumentation typically has a cut-off at $3 \mathrm{~nm}$. This means that when trying to obtain the particle nucleation rate from these measurements, one has to back-calculate down to $1 \mathrm{~nm}(\mathrm{Kul}-$ mala et al., 2001b; Kerminen and Kulmala, 2002). As soon as the particles have been formed, they grow by condensation to larger sizes, but at the same time their concentration is diminished because of collisions with other particles (coagulation). Thus, to get the correct nucleation rate from experimental data, it is essential to know the condensational growth rate in detail.

In the atmosphere, in many cases, it is not known what is the vapour that is condensing onto the freshly nucleated particles, thus causing their growth to observable sizes. The parameters affecting the growth rate are mainly the vapour molecular mass and diameter. In our sample calculations, we thus use several different values for the molecular mass, thus not specifying any detailed species. In Fig. 1, the growth of a particle of density $1000 \mathrm{~kg} / \mathrm{m}^{3}$ is simulated. The condensed material is also assumed to be of the same density, with molecular mass of 50, 100 and $200 \mathrm{amu}$. The vapour concentration is assumed constant $\left(4 \cdot 10^{13} 1 / \mathrm{m}^{3}\right)$. The standard Fuchs-Sutugin results are shown with dotted lines and the results obtained using the corrected model with solid lines. As seen in Fig. 1, it is obvious that particle growth is faster with a vapour with larger molecular size. Also, there is a significant difference in growth rates, when using the corrected expressions compared with the standard Fuchs-Sutugin model, especially at the initial stages of growth when the particle is still very small. Figure 1a shows the evolution of the particle
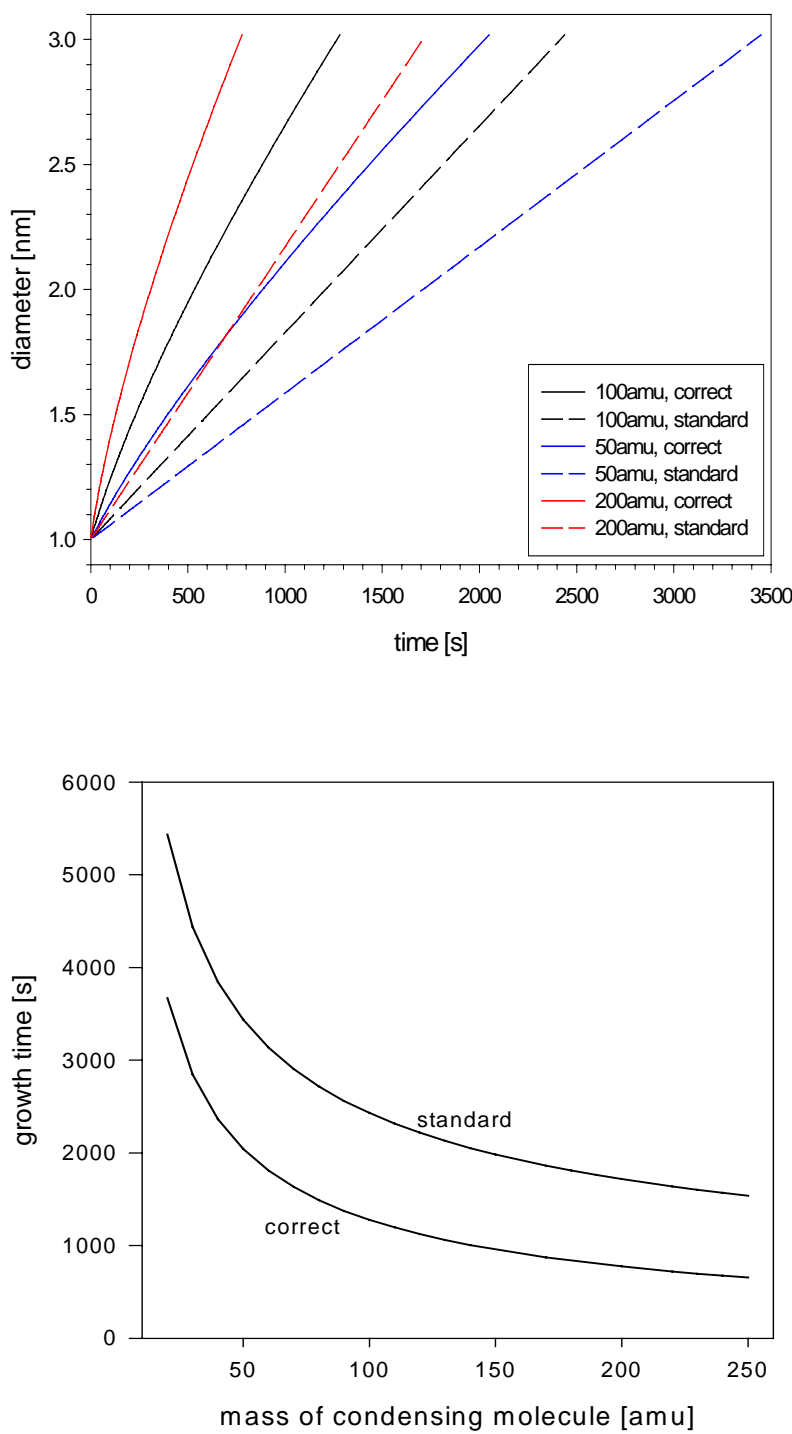

Fig. 1. Condensational growth of freshly nucleated particles from $1 \mathrm{~nm}$ to $3 \mathrm{~nm}$ in diameter, assuming a constant vapour concentration of $4 \cdot 10^{13} 1 / \mathrm{m}^{3}$ : (a) Three different vapour molecular masses (50 amu, $100 \mathrm{amu}, 200 \mathrm{amu}$ ) are used for temporal growth, (b) growth time as a function of molecular mass of condensing molecule. The label correct refers to the method presented in this paper, standard to the unmodified Fuchs-Sutugin expression.

diameter with time for various values of the molecular mass and Fig. $1 \mathrm{~b}$ the growth time as a function of vapour molecular mass. In growth time from $1 \mathrm{~nm}$ to $3 \mathrm{~nm}$, errors more than $100 \%$ can be obtained, if the molecular dimensions and the particle diffusion coefficient are neglected. It must be noted that each simulation is based on assuming constant vapour concentration during growth, and that the same value is used for each run using different molecular masses. Also, since the identity of the vapour(s) causing the growth and thus also their saturation vapour pressures are unknown, a zero surface pressure on the particles was assumed. 
$d N / d\left(\log d_{p}\right)-$ contours

measured result

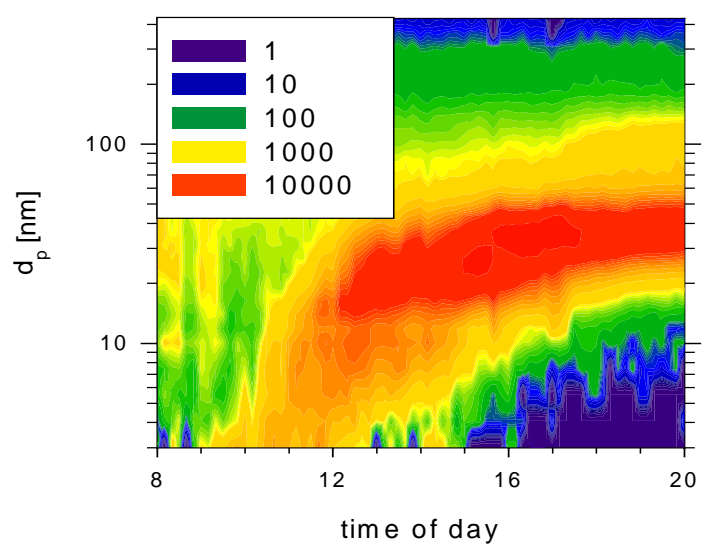

discrete model result

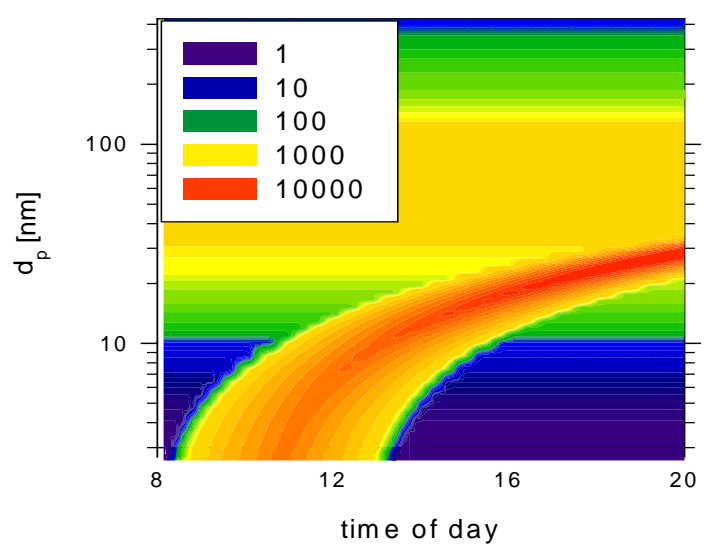

sectional model result

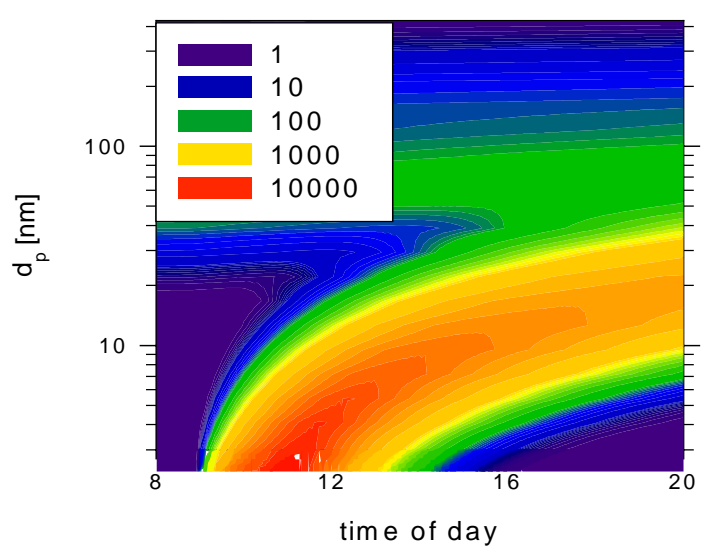

Fig. 2. The measured vs. the modelled particle size distribution in 20 May 1998 in Hyytiälä, Finland. The contour-plot color indicates the particle size distribution height in $1 / \mathrm{cm}^{3}$.
To demonstrate the usefulness of the presented method, we show two simulation results of nucleation events from Hyytiälä measurement station in Finland, in which clear bursts of particle formation, accompanied with subsequent growth, were observed above a boreal forest. One of the events (20 May 1998) was simulated previously by Kulmala et al. (2000), but using a sectional method with a geometrical spacing of size classes. The qualitative agreement between the experiment and the simulation was satisfactory. However, the used sectional method suffers from numerical diffusion and the size distribution narrowing effect, often present in particle growth driven by vapour condensation, is destroyed. The new result, using the discrete method is shown in Fig. 2, together with the experimental result and the result using the sectional method by Kulmala et al. (2000). When compared with the sectional model result there is one very noticeable difference. Now, the maximum values for the distribution density function are not located at $3 \mathrm{~nm}$ (bottom of figure) as is the case for the simulation with numerical diffusion. Instead, now the distribution is first broader, but gradually evolves to a more narrow but higher distribution. The nucleation rate for the simulation was chosen to be identical with the simulation by Kulmala et al. (2000), which means that it was a result of ternary water - sulfuric acid - ammonia nucleation. The background particle concentration was selected to be the measured concentration before the event at 07:00 LT.

The phenomenon can be seen even more clearly, when the experimental results (for 20 May 1998) are presented as in Fig. 3, in which the point wise values of the size distribution are presented for four different particle diameters $(6.082 \mathrm{~nm}$, $9.353 \mathrm{~nm}, 12.30 \mathrm{~nm}$ and $15.83 \mathrm{~nm}$ ), as a function of time. The values correspond to different classes of the particlesizing instrument. In all curves the region left of the peak corresponds to early stages in which the nucleation burst has not even started or growth has not propagated to the size of interest yet. Then the concentration starts increasing and reaches its maximum when the actual maximum of the nucleation mode size distribution is at the corresponding location. The region right to the peak corresponds to time when the peak has already passed the corresponding size. There are, however some particles present, which most probably come from mixing of air. The model assumes a homogenous air parcel, in contrast to the experimental set-up in which the measuring location is fixed but the air around it moves. The clearly observable nucleation peaks in Fig. 3 were fitted by normal distributions (solid lines), from which the peak locations and heights were then extracted.

From the data presented Fig. 3, it is possible to analyse the experimental growth process further. In Fig. 4a the location of the size distribution peak is shown as a function of time, and in Fig. 4b the height of the peak is shown as a function of corresponding particle diameter. From Eq. (1) it is straightforward to deduce that the growth rate of particles in the kinetic regime is almost independent of size, resulting in linear growth (see, e.g. Seinfeld and Pandis, 1998). 

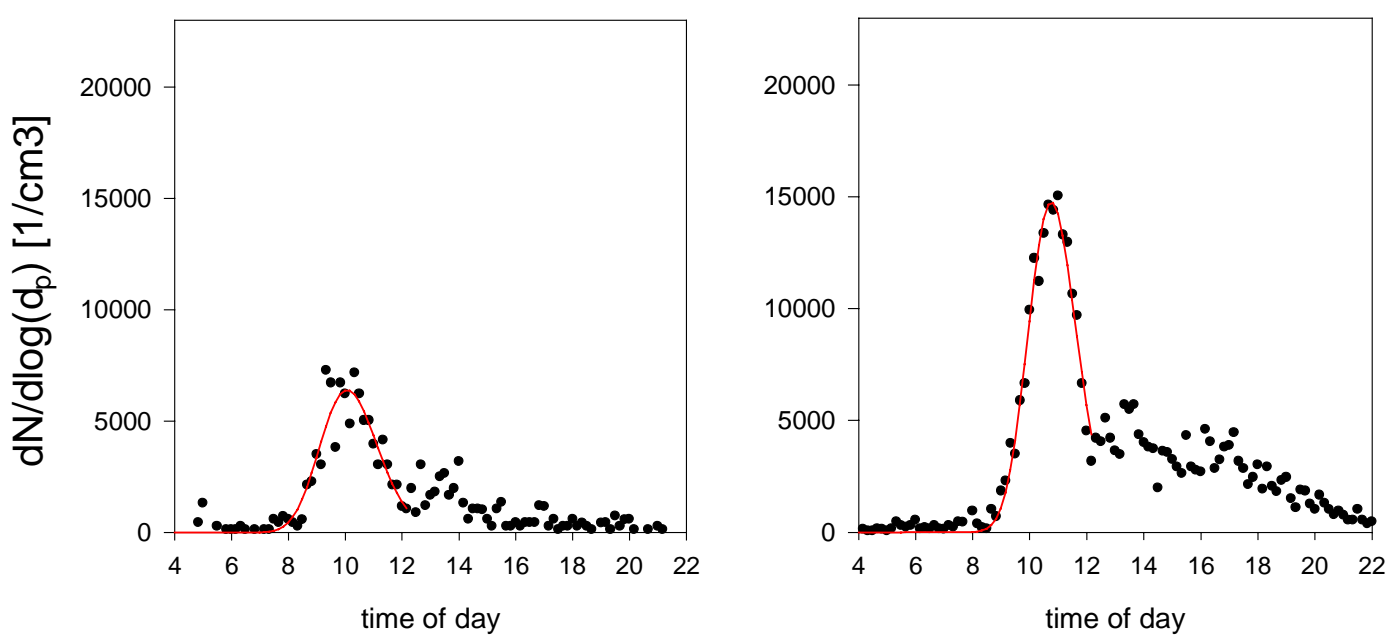

$12.30 \mathrm{~nm}$
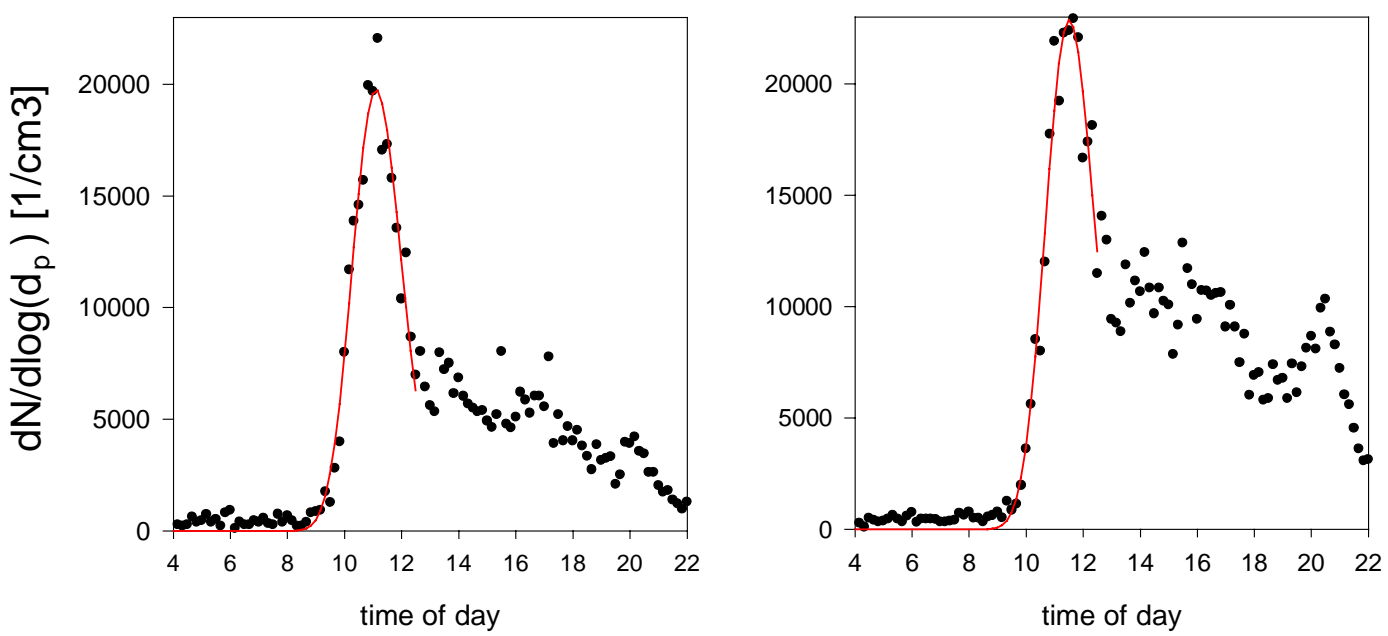

Fig. 3. Evolution of point wise values (at $6.082 \mathrm{~nm}, 9.353 \mathrm{~nm}, 12.30 \mathrm{~nm}$ and $15.63 \mathrm{~nm}$ ) of the particle size distribution in $20 \mathrm{May} 1998$ in Hyytiälä, Finland. The dots represent the measured data, the lines least-squares-fitted Gaussian peaks.

Based on Fig. 4a, growth indeed is linear, supporting theory as well as the assumption that the amount of vapour contributing to the growth process is roughly constant. In Fig. $4 \mathrm{~b}$, the peak height value is based on the typical logarithmic $d N / d\left(\log d_{p}\right)$ form of the size distribution. Thus, since the growth rate in diameter space is constant, and

$\frac{\mathrm{d} N}{d\left(\log d_{p}\right)}=d_{p} \frac{\mathrm{d} N}{d d_{p}}$,

the peak height should increase linearly with diameter (of location). However, this simple chain of thought disregards the fact that the peak height is also lowered because of collisions with background particles. It is, though, evident in Fig. 4b: the peak height increases almost linearly with diameter.
The highest chosen diameter in the analysis, $15.63 \mathrm{~nm}$, corresponds to the size for which there is a clear visible nucleation-originated peak passing through. Above this size, the background particles disturb the analysis. The experimentally observed growth rate $(6.6 \mathrm{~nm} / \mathrm{s})$, for assumed vapour molecules of 100 atomic mass units, is obtained by using a constant value of $4 \cdot 10^{13} 1 / \mathrm{m}^{3}$ for the vapour concentration.

The same analysis works even better for a second modelled event day - 19 May 1999, as shown in Figs. 5a and b. In this case the background particle concentration is lower, resulting in a smaller coagulation sink for the formed particles. Thus there is clear linear growth to much higher sizes than in 20 May 1998. 

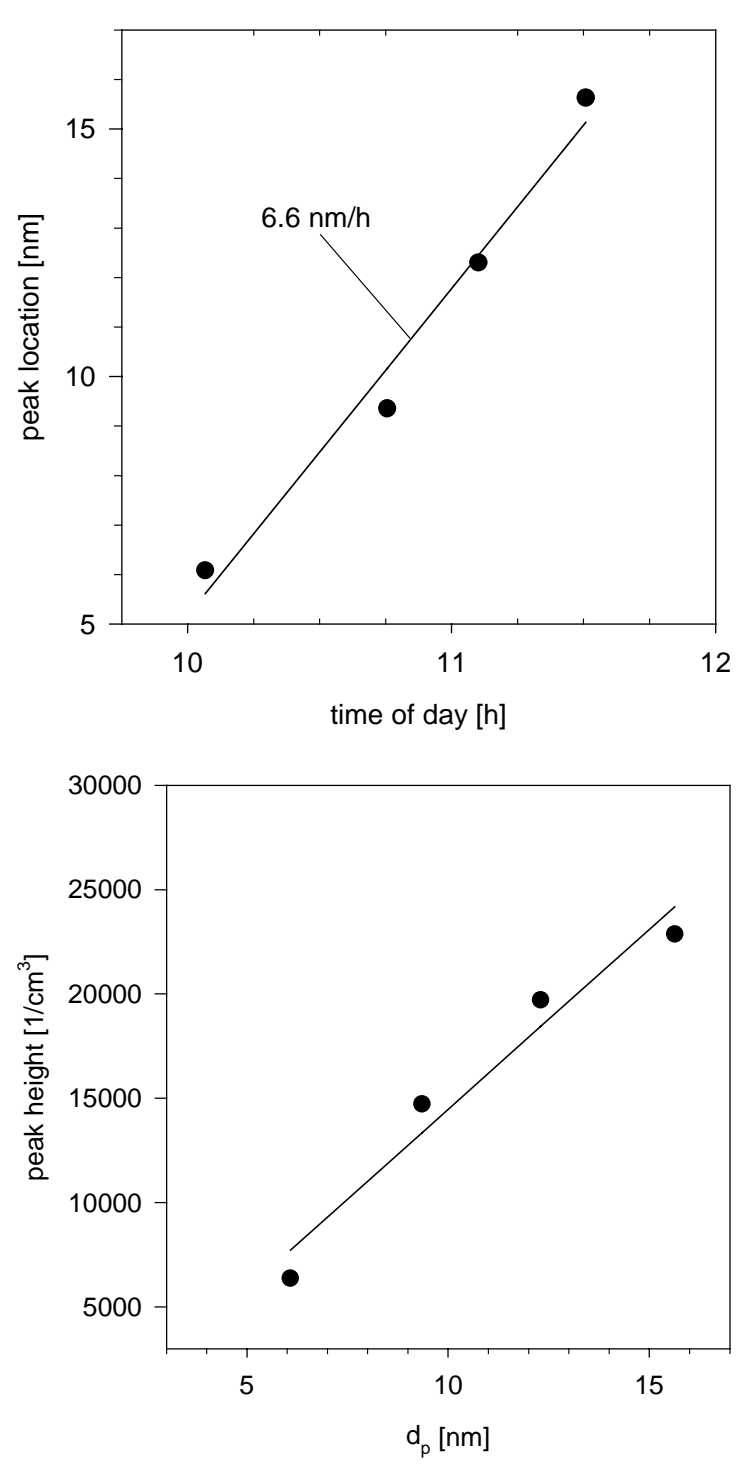

Fig. 4. The peak location as a function of time (a) and peak height as a function of peak location (b) for the nucleation event of 20 May 1998 in Hyytiälä, Finland.

\section{Conclusions}

In this paper, a new model for describing nucleation mode particle growth has been presented. The main new features of the work are a new formulation of the Fuchs-Sutugin expressions for condensational particle growth and the use of a discrete, molecule-by-molecule, simulation method to solve the general dynamic equation of aerosols.

The modification of the Fuchs-Sutugin expression consists of taking into account the molecular dimensions in calculating collision cross sections as well as the particle diffusion coefficient when calculating relative movement of the particle-molecule-system. There is, in principle, nothing novel in this. It is qualitatively how particle-particle col-
19 May 1999
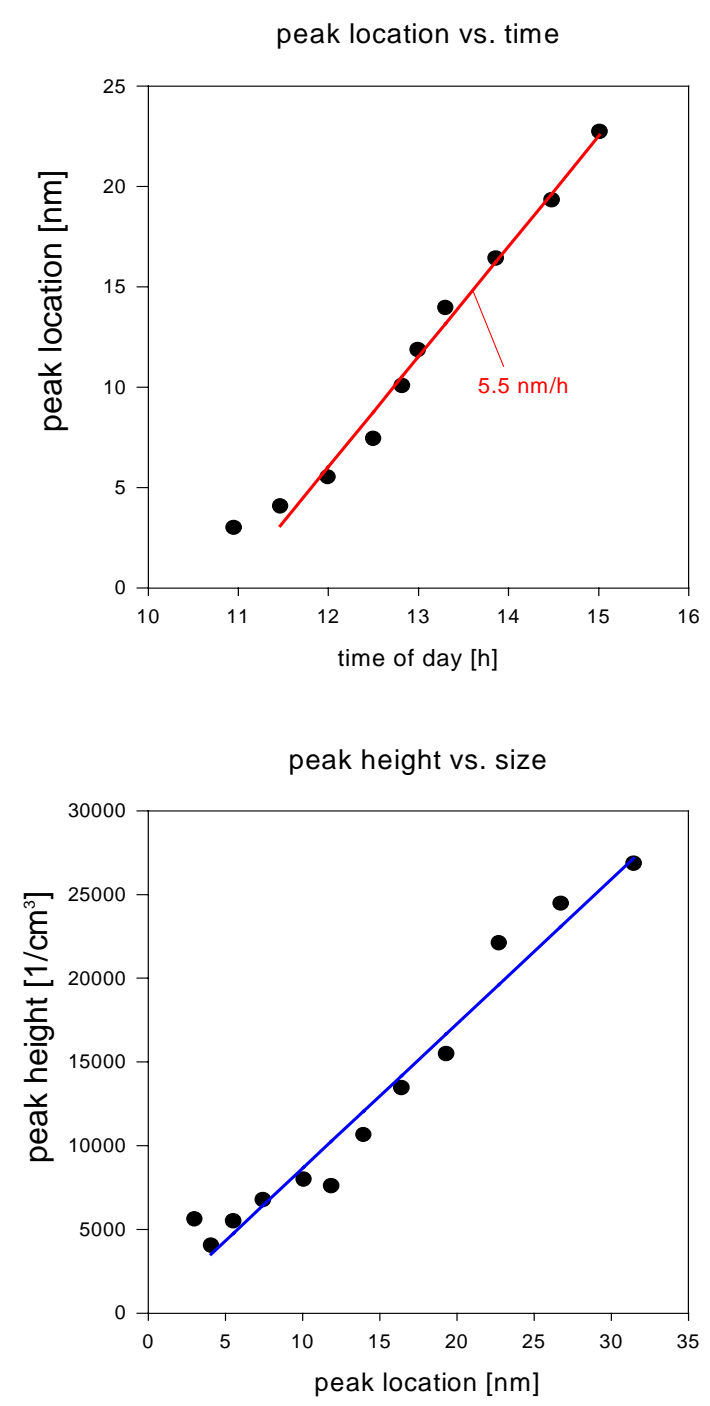

Fig. 5. The peak location as a function of time (a) and peak height as a function of peak location (b) for the nucleation event of 19 May 1999 in Hyytiälä, Finland.

lision frequency functions have been calculated for a long time. However, for condensation it is very typical to use the Fuchs-Sutugin expressions instead of collision theory. It is shown that these effects are far from negligible. For instance, when calculating particle growth from $1 \mathrm{~nm}$ to $3 \mathrm{~nm}$, the effect can be more than a factor of two! For many formationgrowth occurrences in the nature, the molecules responsible for condensational growth can be complex organic or other rather large molecules. Then it is increasingly important to take the above-mentioned effects into account, as shown in the sample calculations of this paper.

The discrete method used in this paper has the advantage of being very easy to program and being free of artificial numerical diffusion problems, that are so often present in sec- 
tional models used in particle size distribution studies. The reason is that, in principle, all physically possible particle sizes are chosen to be size classes. Of course the method is computationally heavy, but as shown in this paper, still feasible for covering the entire nucleation mode dynamics. A comparison with a real natural nucleation-growth event over a boreal forest in Finland, the method seems to capture the key qualitative behaviour of such a system. In a condensation dominated growth process, the numerical diffusion associated with the fixed sectional method makes the distribution artificially wider. However, as shown by the the detailed analysis of the experimentally obtained size distributions in a Finnish forest, the nucleation mode becomes narrower but higher as it propagates through size space. This effect is nicely captured by the discrete method.

Furthermore, the method can be used to validate more approximate but faster methods, in which nucleation, condensation and coagulation are simultaneously present. Analytical solutions for such systems are non-existent, thus a method free of discretisation errors is certainly of value for such validation studies.

\section{References}

Birmilli, W. and Wiedensohler, A.: New particle formation in the continental boundary layer: Meteorological and gas phase parameter influence, Geophys. Res. Lett., 27, 3325, 2000.

Charlson, R. J. and Wigley, T. M. L.: Sulphate aerosol and climatic change, Scientific American, 270, 48-57, 1994.

Clarke, A. D.: Atmospheric nuclei in the remote free troposphere, J. Atmos. Chem., 14, 479-488, 1992.

Covert, D. S., Kapustin, V. N., Quinn, P. K., and Bates, T. S.: New particle formation in the marine boundary layer, J. Geophys. Res., 97, 20 581-20 587, 1992.

Dockery, D. W. and Pope, C. A.: Acute respiratory effects of particulate air pollution, Annu. Rev. Public. Health, 15, 107-132, 1994.

Friedlander, S. K.: Smoke Dust and Haze, Oxford University Press, 2000.

Fuchs, N. A. and Sutugin, A. G.: in: Topics in current aerosol research (Part 2), (Eds) Hidy, G. M., and Brock, J. R., Pergamon, New York, 1971.

Goodrich, F. C.: Nucleation rates and the kinetics of particle growth II: The birth and death process. Proc. R. Soc. London A, 277, 167-182, 1964.

Hegg, D. A., Radke, L. F. and Hobbs, P. V.: Measurements of Aitken nuclei and cloud condensation nuclei in the marine atmosphere and their relation to the DMS-cloud-climate hypothesis, J. Geophys. Res., 96, 18727-18733, 1991.

Hoppel, W. A., Frick, G. M., Fitzgerand, J. W., and Larson, R. E.: Marine boundary layer measurements of new particle formation and the effects nonprecipitating clouds have on aerosol size distribution, J. Geophys. Res., 99, 14 443-14 459, 1994.

Kerminen, N.-M. amd Kulmala, M.: Analytical formulae connecting the "real" and the "apparent" nucleation rate and the nu- clei number concentration for atmospheric nucleation events, $\mathrm{J}$ Aerosol Science, 33, 609-622, 2002.

Kerminen, V.-M. and Wexler, A. S.: The occurrence of sulfuric acid-water nucleation in plumes: Urban environment, Tellus, 48B, 65-82, 1996.

Kulmala M., Pirjola L., and Mäkelä J. M.: Stable sulphate clusters as a source of new atmospheric particles, Nature, 404, 66-69, 2000.

Kulmala, M., Toivonen, A., Mäkelä, J. M., and Laaksonen A.: Analysis of the growth of nucleation mode particles observed in Boreal forest, Tellus 50B, 449-462, 1998.

Kulmala, M., Hämeri, K., Aalto, P., Mäkelä, J. M., Pirjola, L., Nilsson, E. D., Buzorius, G., Rannik, U., Dal Maso, M., Seidl, W., Hoffmann, T., Jansson, R., Hansson, H.-C., Viisanen, Y., Laaksonen, A., and O'Dowd, C. D.: Overview of the international project on Biogenic aerosol formation in the boreal forest (BIOFOR), Tellus 53B, 324-343, 2001a.

Kulmala M., Dal Maso, M., Mäkelä, J. M., Pirjola, L., Väkevä, M., Aalto, P., Miikkulainen, P., Hämeri, K., and O’Dowd, C. D.: On the formation, growth and composition of nucleation mode particles, Tellus 53B, 479-490, 2001b.

Mäkelä, J. M., Aalto, P., Jokinen, V., Pohja, T., Nissinen, A., Palmroth, S., Markkanen, T., Seitsonen, K., Lihavainen, H., and Kulmala, M.: Observations of ultrafine aerosol particle formation and growth in boreal forest, Geophys. Res. Lett., 24, 1219-1222, 1997.

O’Dowd, C., McFiggins, G., Creasey, D. J., Pirjola, L., Hoell, C., Smith, M. H., Allan, B. J., Plane, J. M. C., Heard, D. E., Lee, J. D., Pilling, M. J., and Kulmala, M.: On the photochemical production of new particles in the coastal boundary layer, Geophys. Res. Lett., 26, 1707-1710, 1999.

O’Dowd, C., Aalto, P., Hämeri, K., Kulmala, M., and Hoffmann T.: Atmospheric particles from organic vapours, Nature, 416, 497498, 2002.

Pirjola, L., Laaksonen, A., Aalto, P., and Kulmala, M.: Sulfate aerosol formation in the Arctic boundary layer, J. Geophys. Res., 103, 8309-8322, 1998.

Raes, F., Van Dingenen, R., Cuevas, E., Van Velthoven, P. F. J., and Prospero, J. M.: Observations of aerosols in the free troposphere and marine boundary layer of the subtropical Northeast Atlantic: Discussion of processes determining their size distribution, J. Geophys. Res., 102, 21 315-21 328, 1997.

Schröder, F. and Ström, J.: Aircraft measurements of submicrometer aerosol particles $(>7 \mathrm{~nm})$ in the midlatitude free troposphere and tropopause region, Atmos. Res., 44, 333-356, 1997.

Sahni, D. C.: The effect of a black sphere on the flux distribution of an infinite moderator, J. Nucl. Energy 20, 915-920, 1966.

Seinfeld, J. H. and Pandis, S. N.: Atmospheric Chemistry and Physics, Wiley, New York, 1998.

Wiedensohler, A., Covert, D. S., Swietlicki, E., Aalto, P., Heintzenberg, J., and Leck, C.: Occurrence of an ultrafine particle mode less than $20 \mathrm{~nm}$ in diameter in the marine boundary layer during Arctic summer and autumn, Tellus, 48B, 213-222, 1996.

Zhang, Y., Seigneur, C., Seinfeld, J. H., Jacobson, M. Z., and Binkowski, F.: Simulation of aerosol dynamics: a comparative review of algorithms used in air quality models, Aerosol Sci. Tech. 31, 487-514, 1999. 